Published in final edited form as:

Psychopharmacology (Berl). 2007 October ; 194(3): 309-319.

Increasing the incentive salience of cocaine challenges

preference for pup- over cocaine-associated stimuli during early

postpartum: place preference and locomotor analyses in the

\title{
lactating female rat
}

\author{
Katharine M. Seip ${ }^{\varpi}$ and Joan I. Morrell \\ Center for Molecular and Behavioral Neuroscience, Rutgers University, 197 University Avenue, \\ Newark, NJ 07102, USA
}

\begin{abstract}
Rationale/Objectives-Prior studies using a dual-choice conditioned place preference (CPP) procedure revealed that postpartum female rats (dams) strongly prefer chambers associated with pups over those associated with subcutaneously administered cocaine almost exclusively during early but not late postpartum (Mattson et al. 2001). The present study examines whether early postpartum dams retain strong pup-associated chamber preference when contrasted with a cocaine stimulus of greater incentive salience (intraperitoneal [IP] injections with brief conditioning sessions). Locomotor rate was measured during conditioning (stimuli-present) and test (stimulus-absent) sessions.
\end{abstract}

Materials and methods-A three-chambered CPP apparatus was used to compare preferences for chambers associated with IP cocaine vs age-matched pups. Unconditioned stimuli were systematically assigned to the least-preferred chamber of separate groups of dams before conditioning. Control dams verified that unconditioned stimuli were necessary for CPP and stimulusassociated locomotion.

Results-Compared with most late postpartum dams (60\%), only $31 \%$ of early postpartum dams preferred the cocaine-associated chamber $(P<0.05)$. Substantially more dams preferred the pupassociated chamber during early postpartum $(27 \%)$ than late postpartum $(5 \% ; P<0.05)$. Locomotor sensitization emerged across cocaine-conditioning sessions in cocaine-preferring but not puppreferring dams $(P<0.05)$. Locomotor rates were consistently lower in preferred vs nonpreferred chambers during test.

Conclusions-After increasing cocaine's incentive salience, more early postpartum dams prefer the cocaine-associated chamber than previously reported (Mattson et al. 2001). However, pupassociated chamber preference was still higher in early vs late postpartum. Pup- and cocainepreferring dams expressed differences in the induction phase of locomotor sensitization across cocaine conditioning but expressed similar motoric patterns in their preferred chambers at test.

\section{Keywords}

Maternal; Cocaine; Motivation; Conditioning; Locomotion; Sensitization; Rat; Drug Abuse; Maternal motivation; Conditioned place preference 


\section{Introduction}

Our previous work used a dual-choice conditioned place preference (CPP) procedure to contrast preference for chambers associated with pups vs subcutaneously (SC) administered cocaine in the postpartum female rat (dam). While most dams tested during late postpartum (day 16) preferred the cocaine-associated chamber, most dams tested during early postpartum (day 8) strongly preferred the pup-associated chamber (Mattson et al. 2001). To assess cocaine's absolute reward value in early postpartum, independent of the pup contrast, subsequent CPP studies compared dams' preference for cocaine- vs saline-associated chambers (Wansaw et al. 2003a; Seip et al. 2005). While SC cocaine elicited only moderate chamber preference in both postpartum groups, intraperitoneally (IP) administered cocaine (tested over a range of doses and conditioning lengths) elicited strong chamber preference equally in early and late postpartum.

These recent data led us to question whether early postpartum dams would continue to prefer the pup-associated chamber over a cocaine-associated chamber when the perceptual and motivational properties contributing to cocaine's incentive salience (i.e., route of administration and conditioning session length) were manipulated to enhance cocaine's attractiveness (Robinson and Berridge 1993; Berridge and Robinson 1998; Salamone and Correa 2002). The present study uses dual-choice CPP to assess the strength of pup-associated chamber preference in early and late postpartum dams when contrasted with a chamber associated with a cocaine stimulus of high incentive salience (IP cocaine with short conditioning sessions).

The reward value of cocaine has been well-established in animal models (Pickens and Thompson 1968; Nomikos and Spyraki 1988; Johanson and Fischman 1989; Mayer and Parker 1993; Durazzo et al. 1994; Russo et al. 2003a, b) and human studies (Javaid et al. 1978; Verebey and Gold 1988; Gawin 1991; Volkow et al. 2000; Nelson et al. 2006). While cocaine's reward value is relatively unexplored across postpartum, early postpartum dams bar-press for cocaine at lower rates than virgin females (Hecht et al. 1999). Together with previous CPP work (Mattson et al. 2001), evidence suggests that early postpartum dams may be in a unique state of reward responsivity during which cocaine's incentive salience is actively challenged by pups.

The incentive salience or reward value of a drug can be materially altered by the route of administration (Nomikos and Spyraki 1988; Mayer and Parker 1993; Durazzo et al. 1994; Busse et al. 2005). Chamber preference associated with IP cocaine is well established (Mayer and Parker 1993; Durazzo et al. 1994; Bardo et al. 1995; Russo et al. 2003b) and can be stronger than preference associated with SC cocaine (Mayer and Parker 1993; Bardo et al. 1995). While concentrations of drug in the blood and/or brain may be one of many components mediating drug reward, the extremely rapid increase in concentrations of drug in plasma and/or brain after IP administration (Lau et al. 1991; Festa et al. 2004) compared to SC administration (Vernotica and Morrell 1998; Wansaw et al. 2005) is considered to elicit greater incentive salience, in accord with human subjective reports (Javaid et al. 1978; de Wit et al. 1992; Kollins et al. 1998).

Because of the importance of rapidly increasing plasma concentrations of drug after administration, the length of drug-conditioning sessions can be a critical variable in CPP procedures (Cunningham and Prather 1992; Mayer and Parker 1993; Bardo et al. 1995; Tzschentke 1998; Seip et al. 2005). Compared to shorter sessions, longer sessions that include falling concentrations of the drug can even elicit place aversion responses (Cunningham and Prather 1992). The present study thus uses 30-min IP cocaine-conditioning sessions to maximize chamber exposure during peak plasma concentrations of the drug (Lau et al. 1991; Festa et al. 2004). 
Pups, the second unconditioned stimulus used in the present study, can be uniquely and highly rewarding to the postpartum dam (Wilsoncroft 1969; Hauser and Gandelman 1985; Fleming et al. 1994; Magnusson and Fleming 1995; Lee et al. 2000; Wansaw et al. 2003b; Ferris et al. 2005). Early postpartum dams prefer chambers paired with pups over pup-sized neutral rubber objects after just $15 \mathrm{~min}$ of deprivation from their pups (Wansaw et al. 2003b) and voluntarily stay in the nest for the longest periods of time (Grota and Ader 1969, 1974; Ader and Grota 1970; Stern and Keer 2002); in contrast, late postpartum dams strongly prefer chambers paired with alternative nonpup stimuli, even after $12 \mathrm{~h}$ of pup deprivation, and leave their pups for increasingly longer intervals. While extending the length of pup deprivation before conditioning dramatically increases pups' incentive salience even to late postpartum dams (23 h, Fleming et al. 1994; 22 h, Wansaw et al. 2003b), the present study deprives dams of pups for $2 \mathrm{~h}$ before conditioning to exploit the naturally prominent differences in maternal motivation between early and late postpartum. As longer pup-conditioning session lengths elicit stronger pup-associated CPP (Fleming et al. 1994), pup-conditioning session lengths of $2 \mathrm{~h}$ were chosen to allow dams' full expression of pup-directed maternal behaviors and repeated bouts of nursing (Mattson et al. 2001, 2003).

Control dams were conditioned and tested in an identical procedure, except that pups and cocaine were not present in conditioning chambers. Controls were used to confirm that pup and cocaine stimuli but not conditioning lengths ( $2 \mathrm{~h}$ vs $30 \mathrm{~min}$ ) elicited CPP.

The present study uses a custom-designed place preference apparatus composed of three equalsized chambers. This study also incorporates useful features of both biased and unbiased methods of stimulus-chamber assignment (Bardo et al. 1995; Tzschentke 1998), to further challenge the strength of each stimulus-associated preference. After a preconditioning baseline session, dams were either categorized as lacking chamber preference or as preferring one of the three apparatus chambers. Dams exhibiting a pre-existing chamber preference were assigned to receive either pups or cocaine in the opposite, least-preferred chamber for conditioning, so that postconditioning preference for that chamber would require a substantial increase in time spent in the chamber against which they were "biased" (Nomikos and Spyraki 1988; Calcagnetti and Schechter 1993; Campbell et al. 2000; Cunningham et al. 2003; Le Foll and Goldberg 2005). Dams that lacked chamber preference were randomly assigned to receive each stimulus in one of the conditioning chambers. As each resulting stimulus-assignment group included both dams exhibiting and lacking pre-existing preference, expression of a postconditioning preference for each stimulus-associated chamber required a substantial increase in chamber time in at least half of the dams.

Locomotor rates were recorded during cocaine- and pup-conditioning (stimulus-present) sessions to confirm increased locomotion after cocaine injections and to explore how pups may affect dams' locomotion in the CPP chamber; to our knowledge, the latter is a novel contribution to CPP literature. Locomotion during the postconditioning session characterized locomotion in the absence of both pups and cocaine, as yet unreported using dual-choice CPP.

\section{Materials and methods}

Animals

Subjects ( $n=57$ ) were postpartum female Sprague-Dawley rats (aged 90-120 days) of stock originally obtained from Charles River Laboratories (Wilmington, MA) and raised in the Laboratory Animal Facility at Rutgers University (Newark, NJ) accredited by the American Association for Accreditation of Laboratory Animal Care. All procedures comply with "Principles of laboratory animal care" and "Guidelines for the Care and Use of Mammals in Neuroscience and Behavioral Research" (National Research Council 2003). Females were individually housed in opaque shoebox cages $(25.5 \mathrm{~cm}$ width $\times 47 \mathrm{~cm}$ length $\times 23 \mathrm{~cm}$ height $)$ 
with woodchip bedding and food and water ad libitum and were maintained on a $12 \mathrm{~h}-12 \mathrm{~h}$ light-dark cycle with lights on at 07:00. All females were nulliparous before mating and remained healthy across pregnancy, parturition, and the entire experiment. After parturition, dams and pups were undisturbed for $24 \mathrm{~h}$; all litters were comingled on the day before the procedure began, and eight pups were redistributed as each dam's home cage litter. Details are in Mattson et al. 2001.

Experimental groups of early $(n=26)$ and late $(n=20)$ postpartum dams were exposed to unconditioned stimuli (pups and cocaine) during conditioning between postpartum days 4-7 or $12-15$ and tested on day 8 or 16 , respectively. Control dams (early $n=6$; late $n=5$ ) were similarly conditioned and tested but were not exposed to unconditioned stimuli during conditioning.

\section{Experimental procedure}

Apparatus-The CPP apparatus consisted of three lidded clear Plexiglas chambers custom designed to be of equal size $(27.5 \mathrm{~cm}$ width $\times 21 \mathrm{~cm}$ length $\times 20.5 \mathrm{~cm}$ height $)$. The center chamber not only acted as a passageway but as a neutral alternative space to the two stimulus-associated side chambers to prevent postconditioning preferences based on forced choice (Seip et al. 2006a, b). Center chamber time is thus considered fully in all primary analyses, before comparisons specific to the stimulus-associated side chambers.

Each side chamber contained unique contextual cues of wallpaper (horizontal or vertical blackand-white stripes) and tactile flooring, either small paper squares (ALPHA-dri, Shepherd Specialty Papers, Kalamazoo, MI) or small corn cobs (Bed-o'cobs, The Andersons, Maumee, $\mathrm{OH})$ scattered on solid gray floors. The center chamber had white wallpaper and a solid gray floor. Chambers were connected by manually operated guillotine doors, which could be closed. Luminance (Konica Minolta Luminance Meter LS-100, Japan) was equal in each side chamber.

Five infrared beams traversed the floor of each chamber. Beam breaks made by the dam's body were recorded using an automated interface (Med Associates, St. Albans, VT) configured using MED-PC ${ }^{\circledR}$ Version IV Research Control and Data Acquisition System. Beam breaks recorded the dam's time in each chamber. Locomotor activity was defined operationally as new beam breaks; repeated breaks of the same beam were excluded from analysis. Locomotor activity could not be measured in the center chamber because of the manufacturer's limitations.

Preconditioning baseline session-Each dam was exposed to the apparatus for a single baseline session before conditioning, either on day 1 (early) or 9 (late). Each dam was placed into the center chamber and allowed to freely access all three chambers for $60 \mathrm{~min}$.

Conditioning phase-Experimental dams were separately confined to each cue-associated side chamber containing one of two unconditioned stimuli, pups or cocaine, once a day for 4 consecutive days. Control dams did not receive unconditioned stimuli during equivalent chamber exposures. Daily ordering of pup- and cocaine-conditioning trials did not affect CPP (Mattson et al. 2001, 2003). The cocaine-conditioning session was last each day, ensuring at least $12 \mathrm{~h}$ for residual cocaine to clear from dams' circulation before the next pup-conditioning session.

Pups-Pups were 4-7 or 12-15 days old, age-matched to the early and late postpartum dams, respectively. Two hours before each pup-conditioning session, pups were removed from each dam's home cage and placed into an adjacent cage so that dams were unable to see or physically interact with pups but were exposed to pups' auditory and olfactory stimuli. Pups were demanding of maternal care immediately before pup-conditioning (Pereira and Ferreira 2006). Dams were confined to a side chamber containing five pups for $2 \mathrm{~h}$, starting at 10:00. 
Cocaine-No pup deprivation preceded cocaine conditioning, eliminating potential deprivation-related confounds associated with the noncocaine stimulus. Cocaine hydrochloride in highly purified powdered form was obtained from the National Institute of Drug Abuse (Research Triangle Park, NC) and injected IP (10 mg/kg in 0.9\% saline) into each dam. Dams were immediately confined to the opposite side chamber for $30 \mathrm{~min}$, starting at 15:00. Cocaine did not produce pathology, confirmed by postmortem examination of the peritoneal cavity.

Postconditioning test session-Dams were tested for CPP on the day after the final conditioning session, either postpartum day 8 or 16. Dams were placed into the center chamber and allowed to freely access all three chambers for $60 \mathrm{~min}$. No unconditioned stimuli were present.

\section{Analyses and statistics}

Statistical analyses were performed using SAS for Windows (Version 9.1; SAS Institute, Cary, NC; Cody and Smith 1997) or manually (Siegel 1956; Bruning and Kintz 1987), with $P<0.05$ as the significance level. Nonparametric tests were used when necessary. Preference data are presented as proportions of a population. Chamber times (minutes) and locomotor scores are presented as means and standard errors of the mean.

Conditioned place preference-The time spent in each chamber (chamber time) during pre- and postconditioning sessions was used to identify each dam's chamber preference (Mattson et al. 2001, 2003). Dams that spent at least $30 \mathrm{~min}$ in one chamber and $25 \%$ more time in that chamber than in other chambers were categorized as preferring that chamber. Dams that spent equal amounts of time in each chamber were categorized as lacking preference. Four preference categories resulted: preference for the left, center, or right chamber or no preference. Chamber times were also averaged across all preference categories to represent the entire population.

Within-group comparisons-Empirical preconditioning preferences were compared to theoretical preferences distributed equally among all preference categories (25:25:25:25), using a Chi-squared goodness-of-fit test for specified proportions. Empirical pre- and postconditioning preferences were then compared using another Chi-squared goodness-of-fit test, followed by one-tailed tests for significance of a proportion. Pre- and postconditioning times were compared with a two-way analysis of variance (ANOVA; chamber and session as repeated measures) and select paired $t$ tests or a one-way ANOVA (chamber as repeated) and Tukey's honestly significant difference post-hoc tests.

Between-group comparisons-Preferences were compared using Fisher's exact tests or one-tailed tests for significance of difference between two proportions. Times were compared with a two-way ANOVA (chamber as repeated) and select independent $t$ tests.

Preconditioning chamber preferences and times-Most early (38\%) and late (70\%) postpartum dams lacked preconditioning chamber preference. Dams exhibiting a preference were similarly distributed across left (early 35\%, late 15\%), center $(15 \%, 5 \%)$, and right (12\%, $10 \%)$ preference categories. These empirical preferences differed from a theoretical distribution $\left(\chi^{2}[3, N=46]=20.96, P<0.0001\right)$. Chamber preferences and times were similar across postpartum and grouped for presentation (Fig. 1a, b). Side chamber times were equal, with center time slightly less than left $(F[2,90]=5.01, P<0.01$; Tukey, $P<0.05)$. Data verify the apparatus' relative neutrality.

Assignment of unconditioned stimuli to conditioning chambers-Dams lacking preconditioning chamber preference were randomly assigned to receive either pups or cocaine 
in each side chamber for conditioning. Dams exhibiting a preference were assigned to receive pups (early $n=8$, late $n=4$ ) or cocaine (early $n=8$, late $n=2$ ) in their least-preferred side chamber for conditioning. Importantly, both dams that lacked and expressed preconditioning preference were included in each final stimulus-assignment group, in which either pups (early $n=16$, late $n=12$; Figs. $2 \mathrm{a}$ and $3 \mathrm{a}$ ) or cocaine (early $n=10$, late $n=8$; Figs. $2 \mathrm{~b}$ and $3 \mathrm{~b}$ ) had been assigned to the least-preferred side chamber in a strong subset of dams.

Locomotion-New beam breaks in each side chamber were summed during the postconditioning session and divided by chamber time to produce a locomotor score (rate) for each chamber. To equate conditioning sessions of unequal length ( $30 \mathrm{~min}$ vs $2 \mathrm{~h}$ ), beam breaks during the first $30 \mathrm{~min}$ of each conditioning session were divided by $30 \mathrm{~min}$. Conditioning scores thus represent the entire cocaine-conditioning session and the first quarter of the pupconditioning session. During the remainder of the pup-conditioning session, dams were typically nursing or crouching over their pups; scores did not change after the first $30 \mathrm{~min}$ (see Feigley et al. 1972; Roth and Katz 1979).

Locomotor scores were separated by dams' chamber preference. Scores were similar across postpartum and grouped (Picazo and Fernandez-Guasti 1993; Wansaw et al. 2005). Scores from cocaine-preferring $(n=20)$ and pup-preferring dams $(n=8)$ were analyzed; dams preferring the center or lacking preference were excluded. All control dams' scores were analyzed.

Locomotor scores during conditioning were compared between groups using two-way ANOVAs (day and chamber as repeated measures) and within groups using one-way ANOVAs (chamber as repeated measure). Postconditioning scores from all groups were compared using a one-way ANOVA (group as repeated measure). ANOVAs were followed by Tukey's HSD tests.

\section{Results}

\section{Conditioned place preference}

Evidence of conditioning-Preconditioning chamber preferences (Fig. 2a,b) and times (Fig. 3a,b) were compared to those of postconditioning (Figs. 2c and 3c, respectively), to provide evidence of conditioning in each postpartum and stimulus-chamber assignment group.

In early postpartum, pre- and postconditioning preferences and times differed substantially in groups where pups $\left(\chi^{2}[3, N=16]=27.57, P<0.0001\right.$; chamber $\times$ session interaction, $\left.P>0.05\right)$ and cocaine $\left(\chi^{2}[3, N=10]=86.59\right.$; chamber $\times$ session interaction, $F[2,18]=3.65$; both $\left.P<0.05\right)$ had been assigned to the least-preferred chamber (Figs. 2, 3). Across both groups, most $(60 \%)$ early postpartum dams preferred either the pup- or cocaine-associated chamber after conditioning. More dams for which pups had been least preferred exhibited pup-associated chamber preference after conditioning $(z=-2.16, P<0.05)$, while more dams for which cocaine had been least-preferred exhibited cocaine-associated chamber preference $(z=-2.46, P<0.05)$. Neither pup-nor cocaine-associated chamber times differed after conditioning because of the relatively bimodal distribution of dams preferring these chambers in postconditioning.

In late postpartum dams, chamber preferences and chamber times also differed after conditioning, both when pups $\left(\chi^{2}[3, N=12]=10.08\right.$; chamber $\times$ session interaction, $F[2,22]$ $=5.49$; both $P<0.05)$ and cocaine $\left(\chi^{2}[3, N=8]=194.56\right.$; chamber $\times$ session interaction, $F[2,14]$ $=4.18$; both $P<0.05)$ had been assigned to the least-preferred chamber (Figs. 2, 3). More dams preferred the cocaine-associated chamber in postconditioning, both when pups $(z=2.06$, $P<0.05)$ and even cocaine $(z=-3.26, P<0.05)$ had been least preferred. Few dams preferred the pup-associated chamber; dams collectively spent less time in that chamber in postconditioning, 
even when time was already low $(t[12]=3.18, P<0.01$; cocaine in least-preferred, $t(8)=-2.17$, $P=0.067)$.

Within each postpartum group, preconditioning stimulus-chamber assignment groups produced similar postconditioning preferences and times and were grouped for further analysis.

Comparison of early and late postpartum dams-More dams preferred the cocaineassociated chamber in late postpartum (60\%) than in early postpartum (31\%; $z=2.28, P<0.05)$, while more dams preferred the pup-associated chamber in early postpartum (27\%) than in late postpartum (5\%; $z=-1.95, P<0.05$; Fig. 2c). Overall time in the pup-associated chamber was greater in early vs late postpartum (group $\times$ chamber interaction, $F[2,88]=5.63, P<0.01$; Tukey, $P<0.05$; Fig. 3c). Overall time spent in the cocaine-associated chamber was substantially higher in late vs early postpartum. Late postpartum dams also spent more time in the cocaine- than pup-associated chamber $(t[20]=-4.11, P<0.001)$; this difference was not seen in early postpartum.

\section{Locomotion}

Conditioning-During cocaine-conditioning, locomotor scores of dams exhibiting pup- or cocaine-associated chamber preference (pup- and cocaine-preferring dams, respectively) were significantly higher than those of control dams (cocaine-preferring: main group effect, $F[1$, 29]=17.73, group $\times$ day interaction, $F[3,87]=5.82$, both $P<0.01$; pup-preferring: main group effect, $F[1,17]=22.24, P<0.001$; group $\times$ day interaction, $F[3,51]=2.64, P=0.059$; all Tukey, $P<0.05$; Fig. 4a). Across conditioning, scores increased in cocaine-preferring dams $(F[3,57]$ $=8.11, P<0.001$; Tukey, $P<0.05)$, did not change in pup-preferring dams, and decreased in control dams $(F[3,30]=6.06, P<0.01$; Tukey, $P<0.05)$; see Fig. 4 a for details.

On select pup-conditioning days, scores of cocaine- and pup-preferring dams were higher than those of control dams (cocaine-preferring: main group effect, $F[1,29]=15.12, P<0.001$; Tukey, $P<0.05$; pup-preferring: group $\times$ day interaction, $F[3,51]=2.90, P<0.05$; Tukey, $P<0.05$ ); see Fig. $4 \mathrm{c}$ for details. Scores were lower in pup- than cocaine-preferring dams on the first two conditioning days (main group effect, $F[1,26]=8.05, P<0.01$; Tukey, $P<0.05$ ). Across conditioning, scores decreased in cocaine-preferring $(F[3,570=10.45, P<0.0001$; Tukey, $P<0.05)$ and control dams $(F[3,30]=16.19, P<0.0001$; Tukey, $P<0.05)$ but not pup-preferring dams.

Postconditioning session-In the cocaine-associated chamber, scores were substantially lower in cocaine-preferring dams than both pup-preferring and control dams $(F[2,36]=11.36$, $P<0.001$; Tukey, $P<0.05$; Fig. 4b). Similarly, in the pup-associated chamber, scores were significantly lower in pup-preferring dams than cocaine-preferring and control dams $(F[2,36]$ $=6.29, P<0.01$; Tukey: $P<0.05$; Fig. 4d). Scores were consistently lower in dams' preferred vs nonpreferred chamber (cocaine-preferring: $t[20]=5.68$; pup-preferring: $t[8]=-2.93$; both $P<0.05$ ); the latter of which did not differ from controls. Controls' scores were equal in each side chamber.

\section{Control group}

Preconditioning session-Chamber preferences and times did not differ across postpartum and were grouped. Most (64\%) control dams lacked pre-existing chamber preference; the remaining dams preferred the center chamber (Fig. 5a); thus, dams responded differently than an equal theoretical distribution $\left(\chi^{2}[3, N=11]=12.02, P<0.01\right)$. Side chamber times were equal and lower than in the center chamber $(F[2,20]=4.21, P<0.05$; Tukey, $P<0.05$; Fig. 5b). Session lengths of $2 \mathrm{~h}$ or $30 \mathrm{~min}$ were randomly assigned to side chambers for conditioning. 
Postconditioning session-Postconditioning preferences and times did not differ across postpartum and were grouped. There was no conditioned effect for either side chamber. A few more dams preferred the center chamber, and one dam preferred the empty side chamber paired with the cocaine-conditioning length $\left(30 \mathrm{~min} ; \chi^{2}[2, N=11]=363.02, P<0.0001\right.$; Fig. 5a). Side chamber times remained equal and, in the empty side chamber paired with pup-conditioning length $(2 \mathrm{~h})$, lower than the center chamber $(F[2,20]=4.63, P<0.05$; Tukey, $P<0.05$; Fig. $5 \mathrm{~b})$.

\section{Discussion}

\section{Conditioned place preference}

We have increased the incentive salience of cocaine, one of two stimuli presented in this relative reinforcement procedure, to challenge the strength of maternal motivation previously reported in early postpartum dams (Mattson et al. 2001). The present study reveals a novel difference in the strength of maternal motivation in two distinct groups of early postpartum dams. A considerable proportion of early postpartum dams retain strong pup-associated preference when contrasted with a cocaine stimulus of considerable incentive salience; this group of maternally motivated dams is found exclusively in early but not late postpartum. The present study also reveals a novel subset of cocaine-preferring early postpartum dams, for which the relative reward value of pups was selectively compromised. The bimodal distribution of early postpartum dams' stimulus-associated preferences contrasts sharply with the almost-exclusive preference for the cocaine-associated chamber characterizing late postpartum. Results reveal not only that maternal motivation wanes as the postpartum period progresses but that the strong maternal motivation characterizing early postpartum may be compromised in a subset of dams if pups are presented alongside an alternate stimulus eliciting strong incentive salience.

The dual-choice nature of the present study addresses the relative reinforcement value of both stimuli (Flaherty 1996), which describes a dynamic component of the unique reward state of postpartum. Recent work from our lab reveals that in absolute comparisons, most early and late postpartum dams strongly prefer IP cocaine over saline (Wansaw et al. 2003a; Seip et al. 2005). In the relative comparison of the present study, however, less than half of the early postpartum dams preferred the same IP cocaine stimulus over pups, while most late postpartum dams still preferred IP cocaine. While pups may present an attractive alternative to the incentive salience of cocaine exclusively in early postpartum, some early postpartum dams remain vulnerable to increasingly salient cocaine stimuli: nearly three times as many (31\%) dams preferred IP cocaine over pups than preferred SC cocaine over pups (11\%; Mattson et al. 2001). While relative preference for IP cocaine in early postpartum dams was still substantially lower than in absolute comparisons, late postpartum dams' preference remained consistently high despite administration route or contrasting stimulus' identity (Wansaw et al. 2003a).

As expected, control dams did not express meaningful preference for either side chamber, confirming that unconditioned stimuli, not conditioning session length, produced substantial side chamber preferences. Many controls' center chamber preferences at postconditioning may be attributable to a novelty-induced preference (Bardo et al. 1989; Klebaur and Bardo 1999).

Intentional stimulus-chamber assignments after the preconditioning session revealed strong conditioning effects to pup and cocaine stimuli within independent groups of experimental dams, as expected (Nomikos and Spyraki 1988; Calcagnetti and Schechter 1993; Cunningham et al. 2003; Le Foll and Goldberg 2005). The few center-preferring experimental dams clarify that pup- and cocaine-preferring dams were not exhibiting side chamber preference because of a forced choice, validating use of the three-chambered apparatus.

Endocrinological changes across the postpartum period may importantly contribute to the incentive salience of pups to the postpartum dam. Early postpartum, the period of strongest 
overall maternal motivation (Mattson et al. 2001; Wansaw et al. 2003b), is characterized by relatively low levels of estrogen (E), increasing levels of progesterone (P), and high levels of prolactin compared to late postpartum (Grota and Eik-Nes 1967; Smith and Neill 1977; Taya and Greenwald 1982). As the postpartum period progresses, rising E, decreasing P, and strikingly reduced prolactin gradually return to levels of a cycling female (Grota and Eik-Nes 1967; Smith and Neill 1977; Taya and Greenwald 1982), coinciding with substantially decreased maternal motivation. While these changes occur over a period of days, the two postpartum time points examined in the present study represent fundamentally different endocrinological states that may contribute substantially to the expression of pup-associated chamber preference. While $\mathrm{E}$ and $\mathrm{P}$ are necessary for maternal motivation in ovariectomized virgin female rats (Fleming et al. 1994), however, a contingent relationship between endocrine levels and maternal motivation has yet to be demonstrated in the postpartum female. Further, it remains to be determined whether these endocrinological substrates are distinct from or overlap with those mediating cocaine's reward value (Hecht et al. 1999; Russo et al. 2003a; Carroll et al. 2004; Jackson et al. 2006).

Other nonendocrinological, stimulus-bound properties may also contribute to maternal motivation. While the present study used age-matched pups to mimic the stimuli present in the dam's natural environment, changing physical characteristics accompanying normal pup development may include properties that elicit less incentive salience and thus evoke less maternal motivation. Pups' increasing size and functional capacity coincides with a dramatic reduction in maternal behavior (Bridges et al. 1972; Reisbick et al. 1975; Stern and Mackinnon 1978), while young pups increase the frequency and quality of maternal behavior (Noirot 1964a, b, 1965; Stern and Mackinnon 1978) and activate dopaminergic reward circuits in the brain (Ferris et al. 2005). However, maternal behavior and motivation do not covary in the postpartum dam (Hauser and Gandelman 1985; Mattson et al. 2003). As dams prefer either young or old (age-matched) pups equally in a dual-choice CPP procedure (Wansaw and Morrell, unpublished observations), maternal motivation may be driven not by pups but by undetermined physiological or behavioral changes in the dam that subsequently affect her responsivity to pups across multiple developmental time points.

\section{Locomotion during the place preference procedure}

Locomotion has been analyzed infrequently but usefully within CPP studies (Brockwell et al. 1996; Martin-Iverson et al. 1997; Shimosato and Ohkuma 2000). To our knowledge, locomotor analyses across a dual-choice CPP procedure and within a chamber paired with natural salient stimuli (pups) contribute uniquely to CPP literature.

Rodents experience increased locomotion after cocaine injections (Wise and Bozarth 1987; Yeh and Haertzen 1991; Shimosato and Ohkuma 2000) and may exhibit locomotor sensitization after repeated injections (Post and Rose 1976). The present study not only confirms cocaine-induced locomotion during each cocaine-conditioning session but reveals a unique time course of the induction phase of sensitization in distinct preference populations. Sensitization was induced in cocaine-preferring dams by the third conditioning day but not in pup-preferring dams by the final (fourth) day. Pup-preferring dams may require additional drug exposures for induction to occur. This relationship between cocaine's motoric and reward (incentive) value accords with and extends others' work (Wise and Bozarth 1987; Berridge and Robinson 1995).

Across pup conditioning, locomotion decreased consistently among cocaine-preferring and control dams. A similar reduction may emerge in pup-preferring dams with additional pup exposures. Dams' reduced locomotion across repeated exposures to pups may represent dams' habituation to pups despite pups' ongoing developmental changes. 
During the postconditioning session, locomotor rates were consistently lower in each dam's preferred chamber than her nonpreferred chamber, regardless of the identity of the stimulus (pups or cocaine) associated with each chamber. Compared to locomotion measured in singlechoice CPP procedures (Brockwell et al. 1996; Russo et al. 2003a), this is the first report of a highly consistent locomotor pattern in chambers paired with two distinct stimuli. Conditioned locomotion did not emerge in the pup- or cocaine-associated chamber, the latter despite substantial locomotor sensitization on the final conditioning day. Important procedural differences may explain others' reported conditioned locomotion (Martin-Iverson et al. 1997). Locomotion across CPP thus helps to characterize the incentive salience of distinct stimuli and may predict dams' responsivity to drugs with abuse potential (Wise and Bozarth 1987; Piazza et al. 1989).

\section{Acknowledgements}

This research was supported by NIH DA014025 and March of Dimes \#12FY02-05-103 and \#12FY05-06-134 awarded to JIM. The authors acknowledge Eugenia I. Dziopa for her excellent technical assistance, Dr. Linda Hirsch, NJIT, Newark NJ, for consultation on statistical analyses, and the Laboratory Animal Facility staff of Rutgers University, Newark NJ, for animal breeding and care. All experiments described within this manuscript comply with the current laws of the country in which they were performed. The authors have no conflicts of interest, financial or otherwise, pertaining to any aspect of the work reported in this manuscript.

\section{References}

Ader R, Grota LJ. Rhythmicity in the maternal behaviour of Rattus norvegicus. Anim Behav 1970;18:144-150. [PubMed: 5530113]

Bardo MT, Neisewander JL, Pierce RC. Novelty-induced place preference behavior in rats: effects of opiate and dopaminergic drugs. Pharmacol Biochem Behav 1989;32:683-689. [PubMed: 2544904]

Bardo MT, Rowlett JK, Harris MJ. Conditioned place preference using opiate and stimulant drugs: a meta-analysis. Neurosci Biobehav Rev 1995;19:39-51. [PubMed: 7770196]

Berridge KC, Robinson TE. The mind of an addicted brain: neural sensitization of wanting versus liking. Curr Dir Psychol Sci 1995;4:71-76.

Berridge KC, Robinson TE. What is the role of dopamine in reward: hedonic impact, reward learning, or incentive salience? Brain Res Brain Res Rev 1998;28:309-369. [PubMed: 9858756]

Bridges R, Zarrow MX, Gandelman R, Denenberg VH. Differences in maternal responsiveness between lactating and sensitized rats. Dev Psychobiol 1972;5:123-127. [PubMed: 4671404]

Brockwell NT, Ferguson DS, Beninger RJ. A computerized system for the simultaneous monitoring of place conditioning and locomotor activity in rats. J Neurosci Methods 1996;64:227-232. [PubMed: 8699884]

Bruning, JL.; Kintz, BL. Computational handbook of statistics. 3rd. Scott Foresman; Glenview, IL: 1987.

Busse GD, Freeman KB, Riley AL. The interaction of sex and route of drug administration in cocaineinduced conditioned taste aversions. Pharmacol Biochem Behav 2005;81:814-820. [PubMed: 16005058]

Calcagnetti DJ, Schechter MD. Extinction of cocaine-induced place approach in rats: a validation of the "biased" conditioning procedure. Brain Res Bull 1993;30:695-700. [PubMed: 8457916]

Campbell JO, Wood RD, Spear LP. Cocaine and morphine-induced place conditioning in adolescent and adult rats. Physiol Behav 2000;68:487-493. [PubMed: 10713288]

Carroll ME, Lynch WJ, Roth ME, Morgan AD, Cosgrove KP. Sex and estrogen influence drug abuse. Trends Pharmacol Sci 2004;25:273-279. [PubMed: 15120494]

Cody, RP.; Smith, JK. Applied statistics and the SAS programming language. 4th. Prentice Hall; Upper Saddle River, NJ: 1997.

Cunningham CL, Prather LK. Conditioning trial duration affects ethanol-induced conditioned place preference in mice. Anim Learn Behav 1992;20:187-194.

Cunningham CL, Ferree NK, Howard MA. Apparatus bias and place conditioning with ethanol in mice. Psychopharmacology 2003;170:409-422. [PubMed: 12955296] 
de Wit H, Bodker B, Ambre J. Rate of increase of plasma drug level influences subjective responses in humans. Psychopharmacology 1992;107:352-358. [PubMed: 1615136]

Durazzo TC, Gauvin DV, Goulden KL, Briscoe RJ, Holloway FA. Cocaine-induced conditioned place approach in rats: the role of dose and route of administration. Pharmacol Biochem Behav 1994;49:1001-1005. [PubMed: 7886067]

Feigley DA, Parsons PJ, Hamilton LW, Spear NE. Development of habituation to novel environments in the rat. J Comp Physiol Psychol 1972;79:443-452. [PubMed: 5054479]

Ferris CF, Kulkarni P, Sullivan JM Jr, Harder JA, Messenger TL, Febo M. Pup suckling is more rewarding than cocaine: evidence from functional magnetic resonance imaging and three-dimensional computational analysis. J Neurosci 2005;25:149-156. [PubMed: 15634776]

Festa ED, Russo SJ, Gazi FM, Niyomchai T, Kemen LM, Lin SN, Foltz R, Jenab S, Quinones-Jenab V. Sex differences in cocaine-induced behavioral responses, pharmacokinetics, and monoamine levels. Neuropharmacology 2004;46:672-687. [PubMed: 14996545]

Flaherty, CF. Incentive relativity. Cambridge Univ. Press; New York: 1996.

Fleming AS, Korsmit M, Deller M. Rat pups are potent reinforcers to the maternal animal: effects of experience, parity, hormones, and dopamine function. Psychobiology 1994;22:44-53.

Gawin FH. Cocaine addiction: psychology and neurophysiology. Science 1991;251:1580-1586. [PubMed: 2011738]

Grota LJ, Ader R. Continuous recording of maternal behaviour in Rattus norvegicus. Anim Behav 1969;17:722-729.

Grota LJ, Ader R. Behavior of lactating rats in a dual-chambered maternity cage. Horm Behav 1974;5:275-282. [PubMed: 4477150]

Grota LJ, Eik-Nes KB. Plasma progesterone concentrations during pregnancy and lactation in the rat. J Reprod Fertil 1967;13:83-91. [PubMed: 6066784]

Hauser H, Gandelman R. Lever pressing for pups: evidence for hormonal influence upon maternal behavior of mice. Horm Behav 1985;19:454-468. [PubMed: 4085998]

Hecht GS, Spear NE, Spear LP. Changes in progressive ratio responding for intravenous cocaine throughout the reproductive process in female rats. Dev Psychobiol 1999;35:136-145. [PubMed: 10461127]

Jackson LR, Robinson TE, Becker JB. Sex differences and hormonal influences on acquisition of cocaine self-administration in rats. Neuropsychopharmacology 2006;31:129-138. [PubMed: 15920500]

Javaid JI, Fischman MW, Schuster CR, Dekirmenjian H, Davis JM. Cocaine plasma concentration: relation to physiological and subjective effects in humans. Science 1978;202:227-228. [PubMed: 694530]

Johanson CE, Fischman MW. The pharmacology of cocaine related to its abuse. Pharmacol Rev 1989;41:3-52. [PubMed: 2682679]

Klebaur JE, Bardo MT. The effects of anxiolytic drugs on novelty-induced place preference. Behav Brain Res 1999;101:51-57. [PubMed: 10342399]

Kollins SH, Rush CR, Pazzaglia PJ, Ali JA. Comparison of acute behavioral effects of sustained-release and immediate-release methylphenidate. Exp Clin Psychopharmacol 1998;6:367-374. [PubMed: 9861551]

Lau CE, Imam A, Ma F, Falk JL. Acute effects of cocaine on spontaneous and discriminative motor functions: relation to route of administration and pharmacokinetics. J Pharmacol Exp Ther 1991;257:444-456. [PubMed: 2020002]

Le Foll B, Goldberg SR. Nicotine induces conditioned place preferences over a large range of doses in rats. Psychopharmacology 2005;178:481-492. [PubMed: 15765262]

Lee A, Clancy S, Fleming AS. Mother rats bar-press for pups: effects of lesions of the MPOA and limbic sites on maternal behavior and operant responding for pup-reinforcement. Behav Brain Res 2000;108:215-231. [PubMed: 10701665]

Magnusson JE, Fleming AS. Rat pups are reinforcing to the maternal rat: role of sensory cues. Psychobiology 1995;23:69-75. 
Martin-Iverson MT, Reimer AR, Sharma S. Unbiased cocaine conditioned place preference (CPP) obscures conditioned locomotion, and nimodipine blockade of cocaine CPP is due to conditioned place aversions. Psychopharmacology 1997;130:327-333. [PubMed: 9160848]

Mattson BJ, Williams S, Rosenblatt JS, Morrell JI. Comparison of two positive reinforcing stimuli: pups and cocaine throughout the postpartum period. Behav Neurosci 2001;115:683-694. [PubMed: 11439457]

Mattson BJ, Williams SE, Rosenblatt JS, Morrell JI. Preference for cocaine- or pup-associated chambers differentiates otherwise behaviorally identical postpartum maternal rats. Psychopharmacology 2003;167:1-8. [PubMed: 12607073]

Mayer LA, Parker LA. Rewarding and aversive properties of IP and SC cocaine: assessment by place and taste conditioning. Psychopharmacology 1993;112:189-194. [PubMed: 7871018]

National Research Council. Guidelines for the care and use of mammals in neuroscience and behavioral research. National Academies; Washington, DC: 2003.

Nelson RA, Boyd SJ, Ziegelstein RC, Herning R, Cadet JL, Henningfield JE, Schuster CR, Contoreggi $\mathrm{C}$, Gorelick DA. Effect of rate of administration on subjective and physiological effects of intravenous cocaine in humans. Drug Alcohol Depend 2006;82:19-24. [PubMed: 16144747]

Noirot E. Changes in responsiveness to young in the adult mouse. I. The problematic effect of hormones. Anim Behav 1964a;12:52-58.

Noirot E. Changes in responsiveness in the adult mouse. IV. The effect of an initial contact with a strong stimulus. Anim Behav 1964b;12:442-445.

Noirot E. Changes in responsiveness to young in the adult mouse. III. The effect of immediately preceding performances. Behaviour 1965;24:318-325. [PubMed: 5889162]

Nomikos GG, Spyraki C. Cocaine-induced place conditioning: importance of route of administration and other procedural variables. Psychopharmacology 1988;94:119-125. [PubMed: 3126520]

Pereira M, Ferreira A. Demanding pups improve maternal behavioral impairments in sensitized and haloperidol-treated lactating female rats. Behav Brain Res 2006;175:139-148. [PubMed: 16996623]

Piazza PV, Deminiere JM, Le Moal M, Simon H. Factors that predict individual vulnerability to amphetamine self-administration. Science 1989;245:1511-1513. [PubMed: 2781295]

Picazo O, Fernandez-Guasti A. Changes in experimental anxiety during pregnancy and lactation. Physiol Behav 1993;54:295-299. [PubMed: 8372124]

Pickens R, Thompson T. Cocaine-reinforced behavior in rats: effects of reinforcement magnitude and fixed-ratio size. J Pharmacol Exp Ther 1968;161:122-129. [PubMed: 5648489]

Post RM, Rose H. Increasing effects of repetitive cocaine administration in the rat. Nature 1976;260:731732. [PubMed: 944382]

Reisbick S, Rosenblatt JS, Mayer AD. Decline of maternal behavior in the virgin and lactating rat. J Comp Physiol Psychol 1975;89:722-732. [PubMed: 1236875]

Robinson TE, Berridge KC. The neural basis of drug craving: an incentive-sensitization theory of addiction. Brain Res Brain Res Rev 1993;18:247-291. [PubMed: 8401595]

Roth K, Katz R. Stress, behavioral arousal, and open field activity-a reexamination of emotionality in the rat. Neurosci Biobehav Rev 1979;3:247-263. [PubMed: 542239]

Russo SJ, Festa ED, Fabian SJ, Gazi FM, Kraish M, Jenab S, Quinones-Jenab V. Gonadal hormones differentially modulate cocaine-induced conditioned place preference in male and female rats. Neuroscience 2003a;120:523-533. [PubMed: 12890521]

Russo SJ, Jenab S, Fabian SJ, Festa ED, Kemen LM, Quinones-Jenab V. Sex differences in the conditioned rewarding effects of cocaine. Brain Res 2003b;970:214-220. [PubMed: 12706263]

Salamone JD, Correa M. Motivational views of reinforcement: implications for understanding the behavioral functions of nucleus accumbens dopamine. Behav Brain Res 2002;137:3-25. [PubMed: 12445713]

Seip KM, Reiss JI, Dziopa EI, Wansaw MP, Morrell JI. Further place preference studies on the rewarding effects of cocaine in the postpartum female rat (abstract). Soc Neurosci 2005;35:419.8.

Seip KM, Dziopa EI, Morrell JI. Challenges to preference for pups in early postpartum and cocaine in late postpartum using stringent methodological manipulations to the place preference paradigm (abstract). Soc Neurosci 2006a;36:577.10. 
Seip KM, Dziopa EI, Morrell JI. Dramatic pup avoidance in late postpartum contrasts with preference for pups over cocaine in early postpartum: studies using 2- and 3-chambered place preference paradigms (abstract). Soc Behav Neuroendocrinol 2006b;10:P4.

Shimosato K, Ohkuma S. Simultaneous monitoring of conditioned place preference and locomotor sensitization following repeated administration of cocaine and methamphetamine. Pharmacol Biochem Behav 2000;66:285-292. [PubMed: 10880680]

Siegel, S. Nonparametric statistics for the behavioral sciences. McGraw Hill; New York: 1956.

Smith MS, Neill JD. Inhibition of gonadotropin secretion during lactation in the rat: relative contribution of suckling and ovarian steroids. Biol Reprod 1977;17:255-261. [PubMed: 889995]

Stern JM, Keer SE. Acute hunger of rat pups elicits increased kyphotic nursing and shorter intervals between nursing bouts: implications for changes in nursing with time postpartum. J Comp Psychol 2002;116:83-92. [PubMed: 11926687]

Stern JM, Mackinnon DA. Sensory regulation of maternal behavior in rats: effects of pup age. Dev Psychobiol 1978;11:579-586. [PubMed: 720763]

Taya K, Greenwald GS. Peripheral blood and ovarian levels of sex steroids in the lactating rat. Endocrinol Jpn 1982;29:453-459. [PubMed: 7151743]

Tzschentke TM. Measuring reward with the conditioned place preference paradigm: a comprehensive review of drug effects, recent progress and new issues. Prog Neurobiol 1998;56:613-672. [PubMed: 9871940]

Verebey K, Gold MS. From coca leaves to crack: the effects of dose and routes of administration in abuse liability. Psychiatr Ann 1988;18:513-520.

Vernotica EM, Morrell JI. Plasma cocaine levels and locomotor activity after systemic injection in virgin and in lactating maternal female rats. Physiol Behav 1998;64:399-407. [PubMed: 9748111]

Volkow ND, Wang GJ, Fischman MW, Foltin R, Fowler JS, Franceschi D, Franceschi M, Logan J, Gatley SJ, Wong C, Ding YS, Hitzemann R, Pappas N. Effects of route of administration of cocaine induced dopamine transporter blockade in the human brain. Life Sci 2000;67:1507-1515. [PubMed: 10983846]

Wansaw, MP.; Reiss, J.; Morrell, JI. Dynamic changes in motivation to seek either natural or pharmacological rewards occur as the postpartum period progresses in the rat (abstract). NIDA Symposium Abstract 23, Society for Neuroscience; New Orleans Louisiana. 2003; 2003a.

Wansaw, MP.; Reiss, J.; Morrell, JI. Varying the time dams are deprived of pups has minimal effects on preferences for pup-associated cues in the early, and substantial effects in the late postpartum period. Society for Neuroscience; New Orleans, LO. 2003b. Abstract 23

Wansaw MP, Lin SN, Morrell JI. Plasma cocaine levels, metabolites, and locomotor activity after subcutaneous cocaine injection are stable across the postpartum period in rats. Pharmacol Biochem Behav 2005;82:55-66. [PubMed: 16115667]

Wilsoncroft WE. Babies by bar-press: maternal behavior in the rat. Behav Res Meth Instrum 1969;1:229_ 230.

Wise RA, Bozarth MA. A psychomotor stimulant theory of addiction. Psychol Rev 1987;94:469-492. [PubMed: 3317472]

Yeh SY, Haertzen CA. Cocaine-induced locomotor activity in rats. Pharmacol Biochem Behav 1991;39:723-727. [PubMed: 1784601] 

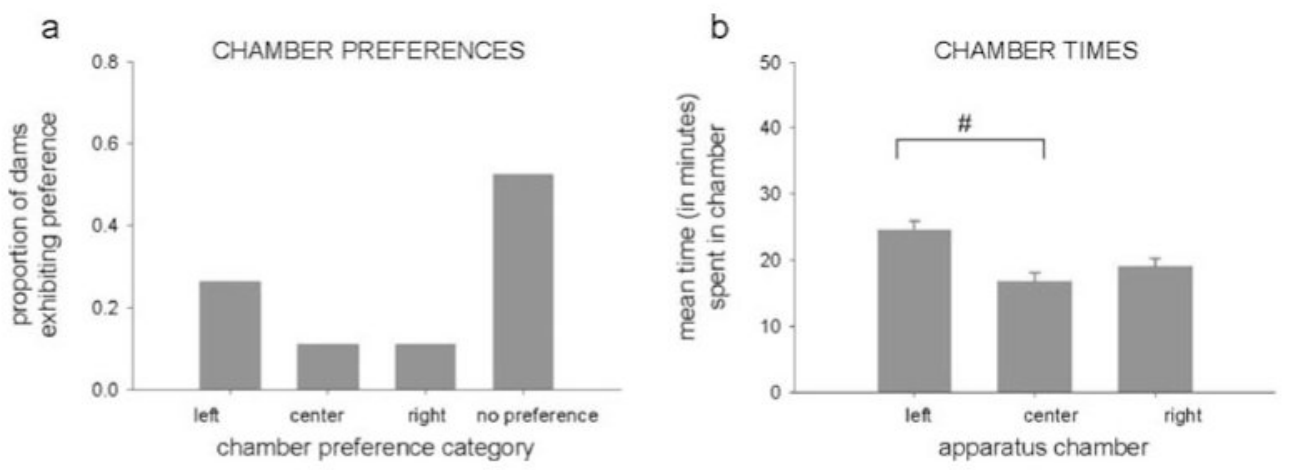

Fig. 1.

Proportion of dams exhibiting preference for each chamber or lacking a chamber preference (a) and mean times spent in each chamber (b) of the three-chambered conditioned place preference (CPP) apparatus during the preconditioning baseline session, before assigning dams to different stimulus-chamber assignment groups. Both graphs include data from both postpartum groups. Proportions of dams placed into each preference category differed significantly from each other; only times in the left and center chambers differed significantly (number sign); both $P<0.05$ 


\section{CHAMBER PREFERENCES}

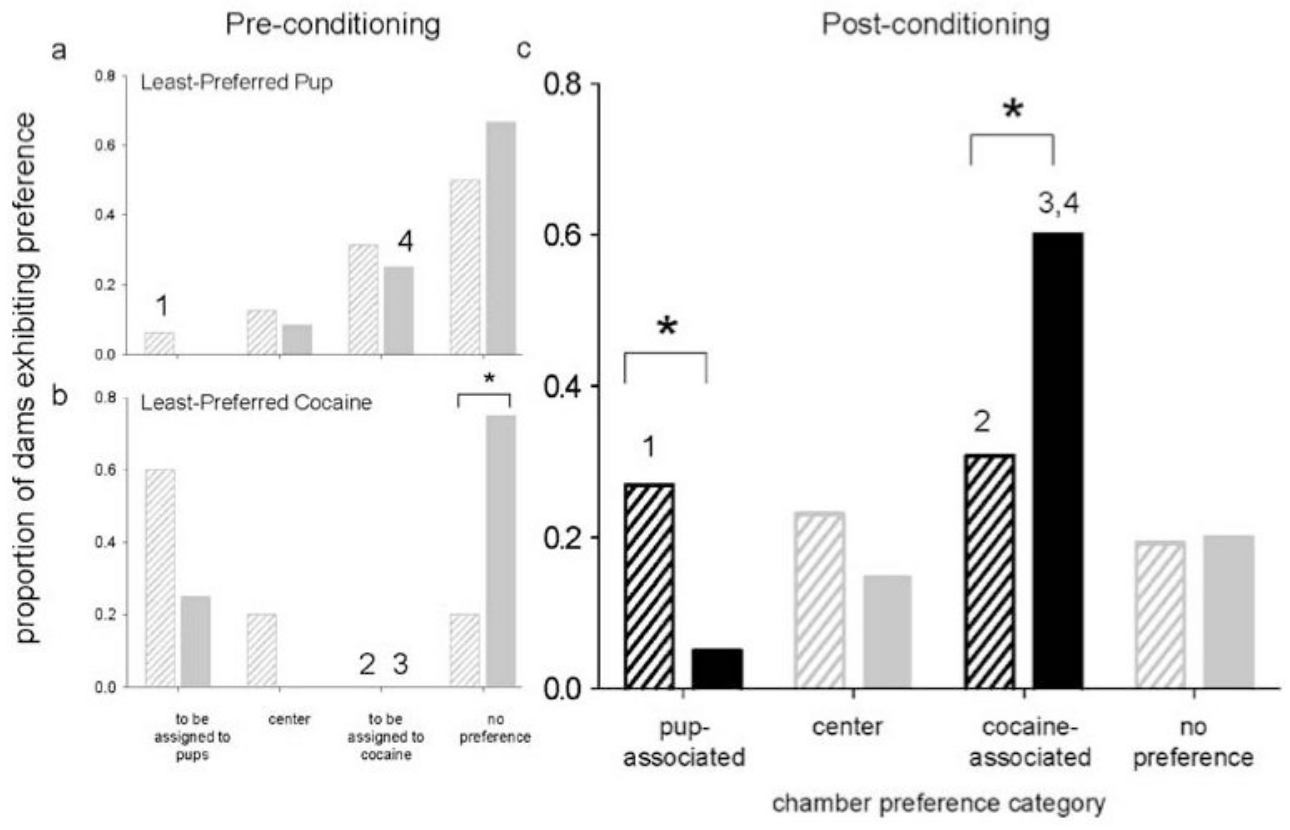

Fig. 2.

Proportion of dams exhibiting preference for each chamber or lacking a chamber preference in the CPP apparatus. Dams were conditioned and tested either during early (striped bars) or late (solid bars) postpartum. Preconditioning chamber preferences are presented separately for each stimulus-chamber assignment group, in which either pups (a) or cocaine (b) were assigned to the least-preferred chamber in most dams. Postconditioning chamber preferences were similar regardless of stimulus-chamber assignment group and were grouped (c). Statistically significant differences are designated with an asterisk for between-group comparisons and corresponding numbers for comparisons between respective pre- and postconditioning groups; all $P<0.05$ 


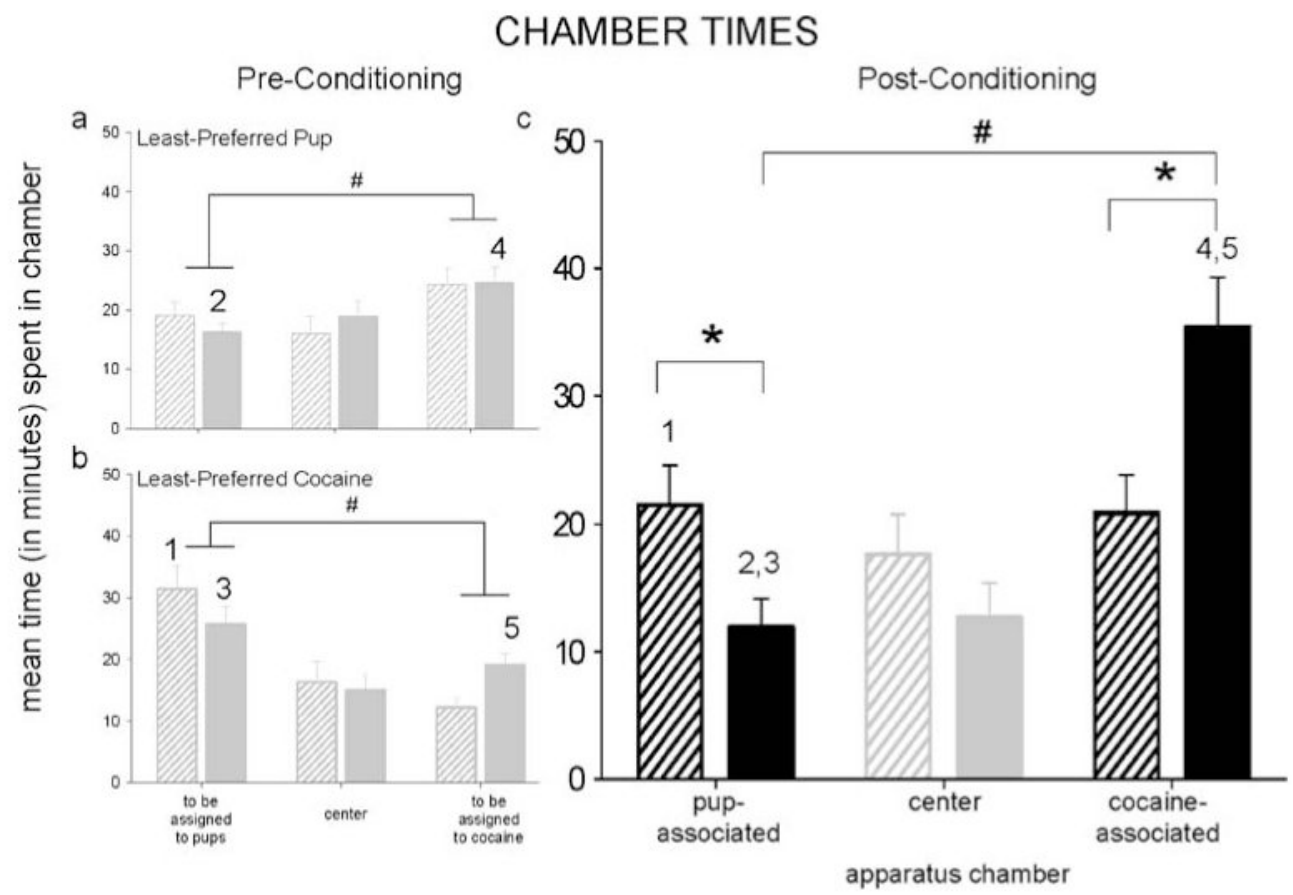

Fig. 3.

Mean time $( \pm$ SEM) spent in each chamber of the CPP apparatus by dams conditioned and tested either during early (striped bars) or late (solid bars) postpartum. Preconditioning chamber times are presented separately for each stimulus-chamber assignment group, in which either pups (a) or cocaine (b) were assigned to the least-preferred chamber in most dams. Postconditioning chamber times were similar regardless of stimulus-chamber assignment group and were grouped (c). Statistically significant differences are designated with an asterisk for between-groups and number sign for within-groups and corresponding numbers for respective pre- and postconditioning groups; all $P<0.05$ except (5) where $P<0.07$ 


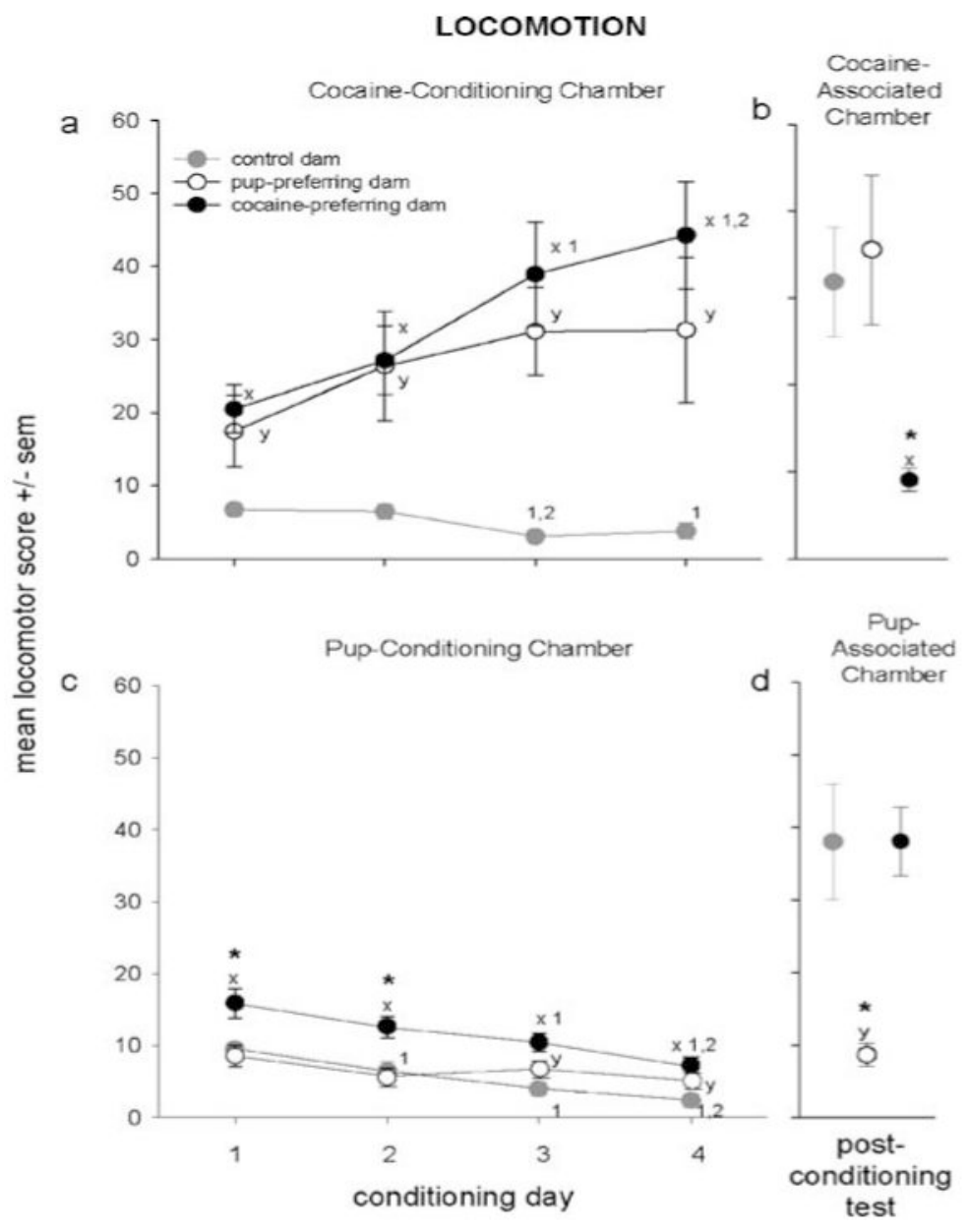

Fig. 4.

Locomotor scores were calculated during all four cocaine-conditioning (a) and pupconditioning (c) sessions, and during the post-conditioning session in the side chamber associated with cocaine (b) and with pups (d). On select conditioning days and during the test session, scores differed significantly between control dams and cocaine-preferring dams (x) or pup-preferring dams (y), and between cocaine- and pup-preferring dams (*). Within each group, conditioning scores that differed from those on another day of conditioning are marked with the number of the day from which they differ, e.g. (1) if different from day 1 . All $P<0.05$ 

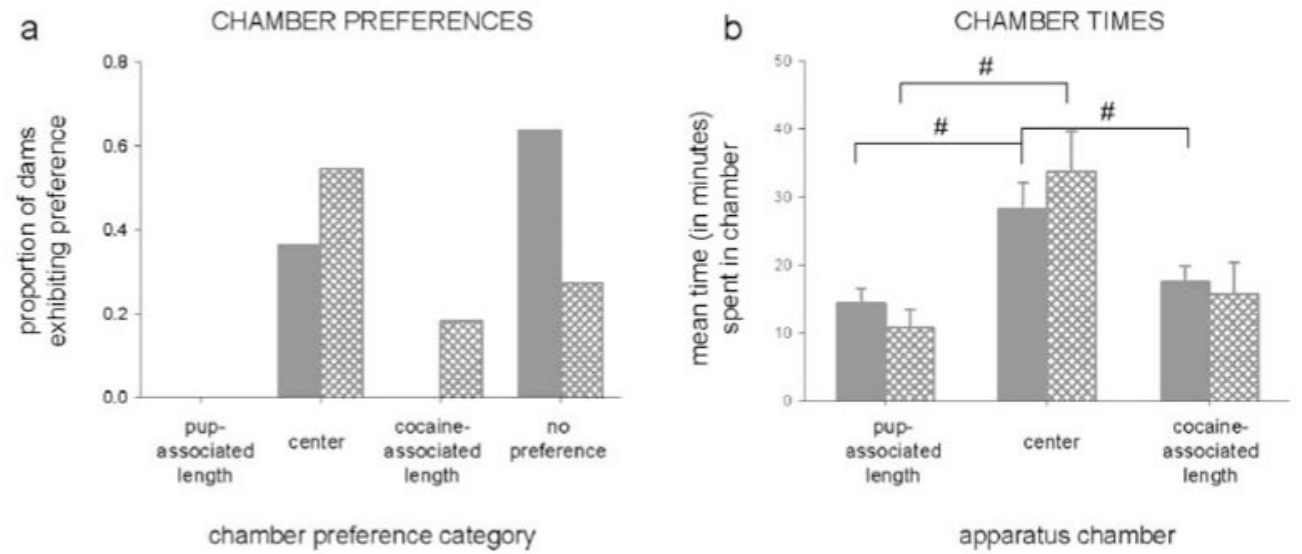

Fig. 5.

Proportion of control dams exhibiting preference for each chamber or lacking a chamber preference (a) and mean times spent in each chamber (b) of the CPP apparatus during the preconditioning (solid bars) and postconditioning (hatched bars) sessions. Control dams were not exposed to unconditioned stimuli in the conditioning chambers but were conditioned for identical lengths as experimental dams, either $2 \mathrm{~h}$ ("pup-associated length") or $30 \mathrm{~min}$ ("cocaine-associated length"). Graphs include data from both postpartum groups. Proportions of dams placed into each preference category differed significantly from each other and differed between sessions; chamber times were equal between side chambers during both sessions but selectively differed from the center chamber (number sign); all $P<0.05$ 